Check for updates

Cite this: RSC Adv., 2017, 7, 18151

Received 26th November 2016 Accepted 21st March 2017

DOI: 10.1039/c6ra27382c

rsc.li/rsc-advances

\section{Synergism between non-ionic and cationic surfactants in a concentration range of mixed monolayers at an air-water interface}

\begin{abstract}
Ahmad Bagheri (D) * and Paresa Khalili
The surface properties and adsorption behavior of mixed binary surfactants containing alkylpyridinium chloride ( $C_{n}$ PC, $n=14$ and 16) and Triton X-100 (TX100) have been studied at $298.15 \mathrm{~K}$. The values of the molecular interaction parameter $\left(\beta^{\mathrm{s}}\right)$ and the mole fraction of components $\left(X_{i}^{\mathrm{s}}\right)$ at the air-water interface in the pre-micellar region were calculated on the basis of Rosen's model. In the new approach, we proposed to estimate surface parameters $\left(\beta^{\mathrm{s}}, X_{i}^{s}, \Gamma_{\mathrm{tot}}, A_{\mathrm{tot}}, \Gamma_{\mathrm{TX} 100}\right.$ and $\left.\Gamma_{\mathrm{C}_{n} \mathrm{PC}}\right)$ in a pre-micellar region, using different fixed values of the surface tension instead of a single-value of surface tension. Then, the influence of surface tension on the surface properties was investigated. The interaction parameter $\left(\beta^{\mathrm{s}}\right)$ is negative at all compositions showing a synergistic effect between the components. The $\beta^{\mathrm{s}}$ was found to considerably decrease (less negative values) with decreasing surface tension due to more migration of TX100 to the surface layer and a reduction in electrostatic self-repulsion between head groups in the ionic surfactant. Also, the total surface area $\left(A_{\text {tot }}\right)$ at the air-water interface decreases with increasing $X_{1}^{\mathrm{s}}$ (mole fraction of TX100 in mixed monolayer) or decreasing surface tension due to the dilution effect on mixing.
\end{abstract}

\section{Introduction}

The interfacial and micellar properties of surfactant mixtures have been extensively studied because of their wide applications, such as hydrate promoters (or inhibitors), biologicals, detergents (foaming), in fabric softening, pharmaceuticals, enhanced oil recovery process etc. $^{\mathbf{1}^{-4}}$ In most cases, the mixture of surfactants often has a better ability to modify the interfacial properties and to generate a high foam volume than the individual surfactants and also the mixtures are advantageous because the purification of a single compound may be too costly and difficult. ${ }^{4-8}$ When two or more surfactants are present in a solution, a mixed monolayer in the interface and mixed micelles in bulk solution are formed as a result of a complex balance of intermolecular forces. Because of this, there have been significant studies on the molecular interactions between various amphiphilic compounds in their binary mixtures (surfactant-surfactant, drug-surfactant and etc.), especially in relation to the existence of synergism or antagonism (negative synergism) between surfactants. Synergism (antagonism) is defined here as the condition in which the properties of the mixture are better (worse) than those achievable with the pure components separately. ${ }^{7-14}$

Although many researchers have studied synergism (or antagonism) between two surfactants at an interface (by calculating the interaction parameter $\left(\beta^{\mathrm{s}}\right)$ and the interfacial mole fractions $\left(X_{i}^{S}\right)$ ), which are conveniently obtained from surface

Department of Chemistry, Semnan University, P.O. Box 35131-19111, Semnan, Iran. E-mail: abagheri@semnan.ac.ir; Fax: +98 2333654057; Tel: +98 2333654057 tension-concentration data using Rosen's model, ${ }^{15-17}$ but almost all papers, these parameters were evaluated at a fixed surface tension value $\left(\approx 45 \mathrm{mN} \mathrm{m}^{-1}\right)$ in pre-micellar region (not at different levels of fixed surface tension). ${ }^{\mathbf{1 6 - 2 3}}$

In the our previous paper, surface tensions of binary mixtures of Triton-X100 (TX100) with a set of two cationic surfactants (tetradecyl pyridinium chloride $\left(\mathrm{C}_{14} \mathrm{PC}\right)$ and hexadecyl pyridinium chloride $\left(\mathrm{C}_{16} \mathrm{PC}\right)$ ) were measured as a function of total concentration using the Du Noüy ring-detachment method. ${ }^{24}$

In the present study, in a new approach, the interaction parameter $\left(\beta^{\mathrm{s}}\right)$ and the mole fraction of surfactant $i\left(X_{i}^{S}\right)$ at the air-water interface (in the above mentioned binary systems) are determined over the whole range of surface tension (at least 9 points) in pre-micellar region, and the influence of surface tension is investigated on the surface parameters $\left(\beta^{\mathrm{s}}\right.$ and $\left.X_{i}^{\mathrm{s}}\right)$.

After estimation of surface parameters $\left(X_{i}^{\mathrm{s}}, \beta^{\mathrm{s}}\right)$, the total surfactant adsorption $\left(\Gamma_{\text {tot }}\right)$, the adsorbed amount of $\mathrm{C}_{n} \mathrm{PC}$ $\left(\Gamma_{\mathrm{C}_{n} \mathrm{PC}}\right)$ and the adsorbed amount of TX100 $\left(\Gamma_{\mathrm{TX} 100}\right)$ were obtained at any fixed surface tension value before CMC. Also, the average surface area per molecule of components $\left(A_{\text {tot }}\right)$ at the air-water interface is determined using the total surfactant adsorption $\left(\Gamma_{\text {tot }}\right)$. The values of $A_{\text {tot }}$ for systems of $\mathrm{C}_{n} \mathrm{PC}(2) /$ TX100(1) decrease with decreasing the mole fraction of surfactant 2 in the total mixed monolayer $\left(X_{2}^{S}\right)$ and the surface tension of mixture at each constant value of the bulk mole fraction $\left(y_{i}\right)$.

The results showed that surface and thermodynamic properties of the mixed monolayer depend on the alkyl chain length of cationic surfactant, surface tension of mixture and ionic-nonionic 
surfactants ratio in the mixed systems. In this work, the experimental data have been collected from our previous paper. ${ }^{24}$

\section{Theory and methods}

\subsection{Composition of mixed adsorbed monolayers}

The nature and intensity of the interaction between two surfactants in the mixed monolayer at the air-water interface can be estimated by determining the values of the interaction parameter $\beta^{\mathrm{s}}$. The interaction parameter $\left(\beta^{\mathrm{s}}\right)$ evaluate the interaction

(a)

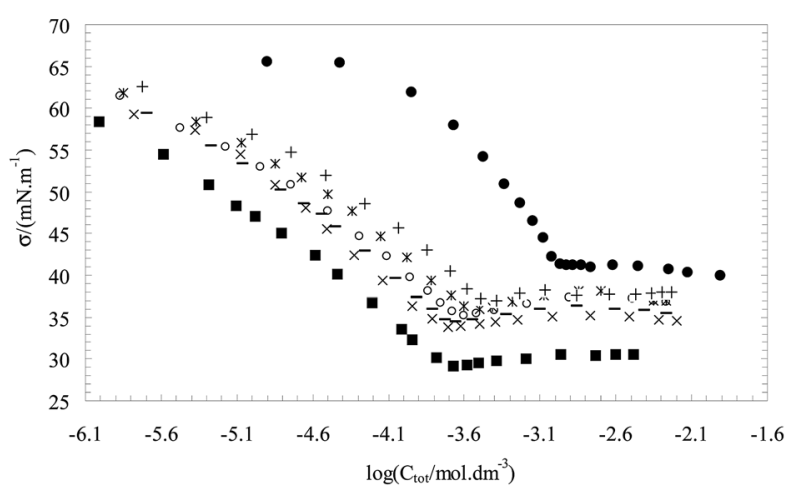

(b)

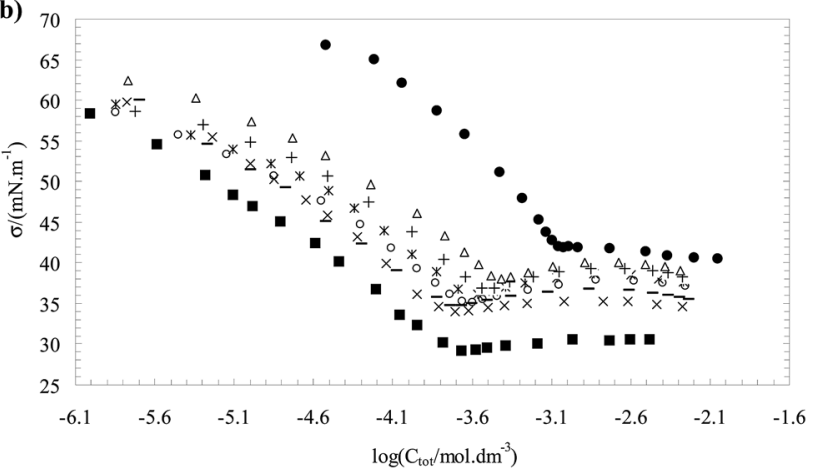

Fig. 1 (a) Plot of the surface tension vs. the total surfactant concentration of the system $\mathrm{C}_{14} \mathrm{PC} / \mathrm{TX} 100$ at different mole fractions of TX100 in solution $\left(y_{1}\right)$ : (O) 0.0, $(+) 0.1999,(*) 0.2948,(O)$ 0.4022, $(-) 0.4986$ $(x) 0.6009$ and ( $)$ 1.0. (b) Plot of the surface tension $v$ s. the total surfactant concentration of the system $\mathrm{C}_{16} \mathrm{PC} / \mathrm{TX} 100$ at different mole fractions of TX100 in solution $\left(y_{1}\right):(\bullet) 0.0,(\Delta)$ 0.1093, $(+)$ 0.1995, $(*)$ 0.2901, (O) $0.3777(-)$ 0.5001, (x) 0.5972 and (口) 1.0 . between two unlike surfactants, relative to the self-interaction of the corresponding pure surfactants before mixing.

A negative value of $\beta^{\mathrm{s}}$ indicates that interactions in mixed monolayer at the air-water interface are more attractive than the self-interaction of the two surfactants prior to mixing. However, a positive value of $\beta^{\text {s }}$ indicates that the attractive interaction of the two different surfactants with each other in mixed monolayer is weaker than the average attractive interaction of the two surfactants before mixing.. ${ }^{13,14}$

The interaction (attraction or repulsion) between two surfactant in the mixed micellar system was further analyzed using Rubingh's model (regular solution theory). ${ }^{7,15,25}$

In this work, the interaction parameter at interface $\left(\beta^{\mathrm{s}}\right)$ is calculated using eqn (1) and (2). eqn (1) is solved iteratively for $X_{1}^{\mathrm{s}}$ which is then substituted into eqn (2) to calculate $\beta^{\mathrm{s}}$. This idea was initially proposed by Rosen and Hua which is based upon the application of the regular solution theory and Rubingh's model: ${ }^{16,17}$

$$
\begin{gathered}
\left(X_{1}^{\mathrm{s}}\right)^{2} \ln \left(\frac{y_{1} C_{12}}{X_{1}^{\mathrm{s}} C_{1}}\right)=\left(1-X_{1}^{\mathrm{s}}\right)^{2} \ln \left(\frac{\left(1-y_{1}\right) C_{12}}{\left(1-X_{1}^{\mathrm{s}}\right) C_{2}}\right) \\
\beta^{\mathrm{s}}=\frac{1}{\left(1-X_{1}^{\mathrm{s}}\right)^{2}} \ln \frac{y_{1} C_{12}}{X_{1}^{\mathrm{s}} C_{1}}
\end{gathered}
$$

Table $1 C_{1}^{\mathrm{TX} 100}, C_{2}^{C_{14} \mathrm{PC}}$ and $C_{2}^{C_{16} \mathrm{PC}}$ are the molar concentration of TX100, $C_{14} P C$ and $C_{16} P C$ surfactants at various fixed values of surface tension $(\sigma)$ in pre-micellar region respectively

\begin{tabular}{llll}
\hline$\sigma /(\mathrm{mN}$ & $\begin{array}{l}C_{1}^{\mathrm{TX} 100} / \\
\left.\mathrm{m}^{-1}\right)\end{array}$ & $\begin{array}{l}C_{2}^{\mathrm{C}_{14} \mathrm{PC}} \\
\left(\mathrm{mmol}^{-1} \mathrm{dm}^{-3}\right)\end{array}$ & $\begin{array}{l}C_{2}^{\mathrm{C}_{16} \mathrm{PC}} \\
\left(\mathrm{mmol}^{-1} \mathrm{dm}^{-3}\right)\end{array}$ \\
\hline 52 & 0.0138 & 0.4113 & 0.3454 \\
51 & 0.0149 & 0.4564 & 0.3828 \\
50 & 0.0160 & 0.5066 & 0.4229 \\
49 & 0.0171 & 0.5608 & 0.4658 \\
48 & 0.0182 & 0.6180 & 0.5119 \\
47 & 0.0191 & 0.6768 & 0.5613 \\
46 & 0.0203 & 0.7362 & 0.6143 \\
45 & 0.0218 & 0.7951 & 0.6710 \\
44 & 0.0239 & 0.9522 & 0.7318 \\
43 & 0.0267 & - & 0.7969
\end{tabular}
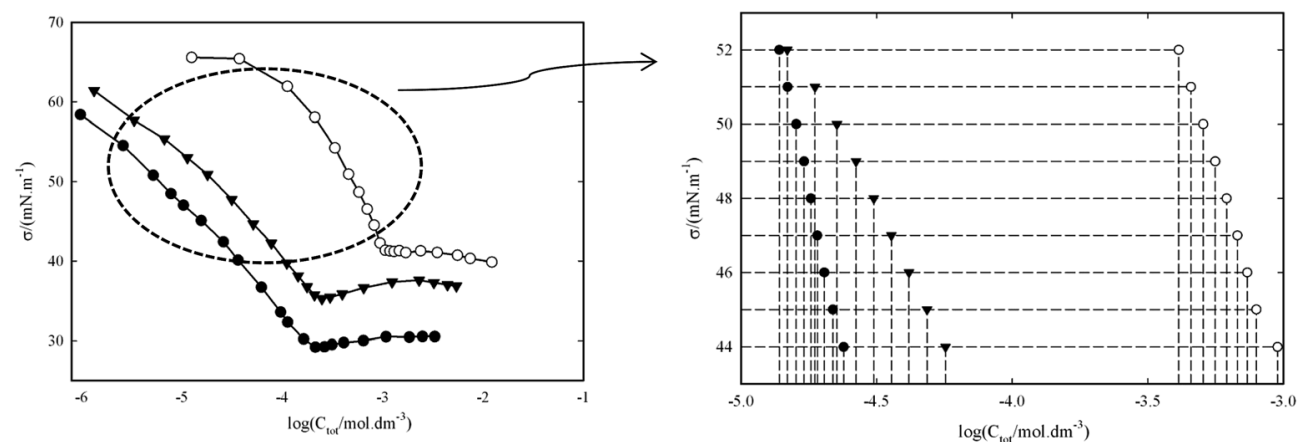

Fig. 2 (Left) the values of surface tension, $\sigma$, against $\log C_{\text {tot }}$, for aqueous solutions of the two pure surfactants $T X-100(-)$ and $C_{14} P C(O)$ as well as of a mixture for which $y_{T \times 100}=0.4022(\boldsymbol{\nabla})$. (Right) the values of surface tension, $\sigma$, against log $C_{\text {tot, }}$ in the various fixed values of surface tension in pre-micellar region for calculations of $C_{1}, C_{2}$ and $C_{12}$. All points (in right figure) represent fitted data of the experimental data (from left figure) with a quadratic function. 
Table $2 C_{12}$ is the molar concentration of surfactant mixture at various fixed values of surface tension $(\sigma)$ in pre-micellar region, $X_{1}^{s}$ (the mole fraction of TX100) and $X_{2}^{s}$ (the mole fraction of $C_{14} \mathrm{PC}$ ) in interface, $\Gamma_{\text {tot }}, \Gamma_{1}$ and $\Gamma_{2}$ are the total surfactant adsorption, the TX100 adsorption and the $\mathrm{C}_{14} \mathrm{PC}$ adsorption respectively, and $A_{\text {tot }}$ is the average surface area per molecule of components

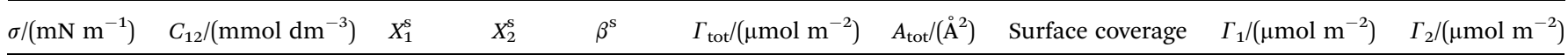

For $\mathrm{C}_{14} \mathrm{PC}(2) / \mathrm{TX100}(1)$ at $y_{1}=0.1999$

$\begin{array}{llllll}52 & 0.0311 & 0.6719 & 0.3281 & -3.75 & 2.142 \\ 51 & 0.0372 & 0.6890 & 0.3110 & -3.29 & 2.205 \\ 40 & 0.0444 & 0.7078 & 0.2922 & -2.85 & 2.267 \\ 48 & 0.0527 & 0.7318 & 0.2682 & -2.38 & 2.327 \\ 47 & 0.0624 & 0.7640 & 0.2360 & -1.84 & 2.387 \\ 46 & 0.0738 & 0.8072 & 0.1928 & -1.22 & 2.445 \\ 45 & 0.0870 & 0.8644 & 0.1356 & -0.48 & 2.503 \\ & 0.1023 & 0.9346 & 0.0654 & -0.52 & 2.560\end{array}$

For $\mathrm{C}_{14} \mathrm{PC}(2) / \mathrm{TX100}(1)$ at $y_{1}=\mathbf{0 . 2 9 4 8}$

$\begin{array}{llllll}52 & 0.0212 & 0.6915 & 0.3085 & -4.47 & 2.049 \\ 51 & 0.0266 & 0.7159 & 0.2841 & -3.77 & 2.137 \\ 50 & 0.0318 & 0.7368 & 0.2632 & -3.28 & 2.210 \\ 49 & 0.0372 & 0.7587 & 0.2413 & -2.85 & 2.272 \\ 48 & 0.0431 & 0.7845 & 0.2155 & -2.40 & 2.329 \\ 47 & 0.0497 & 0.8165 & 0.1835 & -1.90 & 2.386 \\ 46 & 0.0573 & 0.8556 & 0.1444 & -1.32 & 2.448 \\ 45 & 0.0663 & 0.9013 & 0.0987 & -0.64 & 2.500 \\ 44 & 0.0770 & 0.9491 & 0.0509 & -0.13 & 2.559\end{array}$

For $\mathrm{C}_{14} \mathrm{PC}(2) / \mathrm{TX100}(1)$ at $y_{1}=\mathbf{0 . 4 0 2 3}$

$\begin{array}{llllll}52 & 0.0148 & 0.6996 & 0.3004 & -5.39 & 2.006 \\ 51 & 0.0188 & 0.7235 & 0.2765 & -4.63 & 2.085 \\ 50 & 0.0226 & 0.7437 & 0.2563 & -4.09 & 2.146 \\ 49 & 0.0266 & 0.7646 & 0.2354 & -3.62 & 2.200 \\ 48 & 0.0309 & 0.7893 & 0.2107 & -3.14 & 2.250 \\ 47 & 0.0358 & 0.8200 & 0.1800 & -2.59 & 2.299 \\ 46 & 0.0416 & 0.8581 & 0.1419 & -1.95 & 2.349 \\ 45 & 0.0485 & 0.9042 & 0.0958 & -1.18 & 2.400 \\ 44 & 0.0568 & 0.9558 & 0.0442 & -0.24 & 2.452\end{array}$

For $\mathrm{C}_{14} \mathrm{PC}(2) / \mathrm{TX100}(1)$ at $y_{1}=0.4986$

$\begin{array}{llllll}52 & 0.0119 & 0.7088 & 0.2912 & -5.98 & 2.006 \\ 51 & 0.0148 & 0.7302 & 0.2698 & -5.26 & 2.085 \\ 50 & 0.0178 & 0.7491 & 0.2509 & -4.73 & 2.146 \\ 49 & 0.0210 & 0.7694 & 0.2306 & -4.23 & 2.200 \\ 48 & 0.0246 & 0.7936 & 0.2064 & -3.71 & 2.250 \\ 47 & 0.0286 & 0.8233 & 0.1767 & -3.13 & 2.299 \\ 46 & 0.0333 & 0.8595 & 0.1405 & -2.47 & 2.349 \\ 45 & 0.0388 & 0.9018 & 0.0982 & -1.71 & 2.400 \\ 44 & 0.0453 & 0.9472 & 0.0528 & -0.89 & 2.452\end{array}$

For $\mathrm{C}_{14} \mathrm{PC}(2) / \mathrm{TX100}(1)$ at $y_{1}=0.6009$

$\begin{array}{llllll}52 & 0.0150 & 0.7880 & 0.2120 & -4.32 & 2.528 \\ 51 & 0.0171 & 0.8043 & 0.1957 & -3.98 & 2.556 \\ 50 & 0.0189 & 0.8132 & 0.1868 & -3.82 & 2.578 \\ 49 & 0.0207 & 0.8211 & 0.1789 & -3.70 & 2.597 \\ 48 & 0.0227 & 0.8316 & 0.1684 & -3.53 & 2.616 \\ 47 & 0.0249 & 0.8458 & 0.1542 & -3.29 & 2.636 \\ 46 & 0.0276 & 0.8641 & 0.1359 & -2.95 & 2.658 \\ 45 & 0.0311 & 0.8854 & 0.1146 & -2.54 & 2.683 \\ 44 & 0.0355 & 0.9083 & 0.0917 & -2.21 & 2.711\end{array}$

where $X_{1}^{s}$ is the mole fraction of surfactant 1 in the total mixed monolayer; $C_{1}, C_{2}$ and $C_{12}$ are the molar concentration in the solution phase of surfactant 1 , surfactant 2 and their mixture in pre-micellar region, respectively (at the bulk mole fraction of surfactant 1 or $y_{1}$ ).

$\begin{array}{llll}77.54 & 0.70 & 1.439 & 0.703 \\ 75.32 & 0.73 & 1.517 & 0.686 \\ 73.28 & 0.75 & 1.604 & 0.662 \\ 71.38 & 0.78 & 1.703 & 0.624 \\ 69.60 & 0.80 & 1.823 & 0.563 \\ 67.93 & 0.81 & 1.974 & 0.471 \\ 66.37 & 0.83 & 2.163 & 0.339 \\ 64.90 & 0.86 & 2.392 & 0.167\end{array}$

$\begin{array}{llll}81.06 & 0.73 & 1.439 & 0.703 \\ 77.67 & 0.75 & 1.517 & 0.686 \\ 75.17 & 0.77 & 1.605 & 0.662 \\ 73.12 & 0.80 & 1.703 & 0.624 \\ 71.31 & 0.82 & 1.823 & 0.563 \\ 69.62 & 0.84 & 1.974 & 0.471 \\ 68.00 & 0.86 & 2.164 & 0.339 \\ 66.43 & 0.87 & 2.392 & 0.167 \\ 64.92 & 0.88 & 1.439 & 0.703\end{array}$

$\begin{array}{llll}82.81 & 0.72 & 1.403 & 0.603 \\ 79.69 & 0.75 & 1.508 & 0.576 \\ 77.40 & 0.77 & 1.596 & 0.5501 \\ 75.51 & 0.79 & 1.682 & 0.518 \\ 73.82 & 0.81 & 1.776 & 0.474 \\ 72.24 & 0.82 & 1.885 & 0.414 \\ 70.71 & 0.85 & 2.016 & 0.333 \\ 69.21 & 0.86 & 2.170 & 0.230 \\ 67.75 & 0.88 & 2.344 & 0.108\end{array}$

$\begin{array}{llll}82.81 & 0.72 & 1.403 & 0.603 \\ 79.69 & 0.75 & 1.508 & 0.576 \\ 77.40 & 0.77 & 1.596 & 0.550 \\ 75.51 & 0.79 & 1.682 & 0.518 \\ 73.82 & 0.81 & 1.776 & 0.474 \\ 72.24 & 0.82 & 1.885 & 0.414 \\ 70.71 & 0.85 & 2.016 & 0.333 \\ 69.21 & 0.86 & 2.170 & 0.230 \\ 67.75 & 0.88 & 2.344 & 0.108\end{array}$

$\begin{array}{llll}65.72 & 0.82 & 1.992 & 0.536 \\ 65.00 & 0.83 & 2.056 & 0.500 \\ 64.44 & 0.84 & 2.096 & 0.481 \\ 63.97 & 0.85 & 2.132 & 0.465 \\ 63.51 & 0.85 & 2.175 & 0.441 \\ 63.03 & 0.86 & 2.229 & 0.406 \\ 62.50 & 0.87 & 2.297 & 0.361 \\ 61.92 & 0.87 & 2.375 & 0.308 \\ 61.28 & 0.88 & 2.462 & 0.249\end{array}$

In this work, the values of $C_{1}, C_{2}$ and $C_{12}$ are obtained from the surface tension versus concentration plots ( $\sigma-C$ curves) of aqueous solutions of the individual surfactants and their mixtures at a given surface tension value which is in range of $\approx 42$ to $52 \mathrm{mN} \mathrm{m}^{-1}$ in pre-micellar region. 


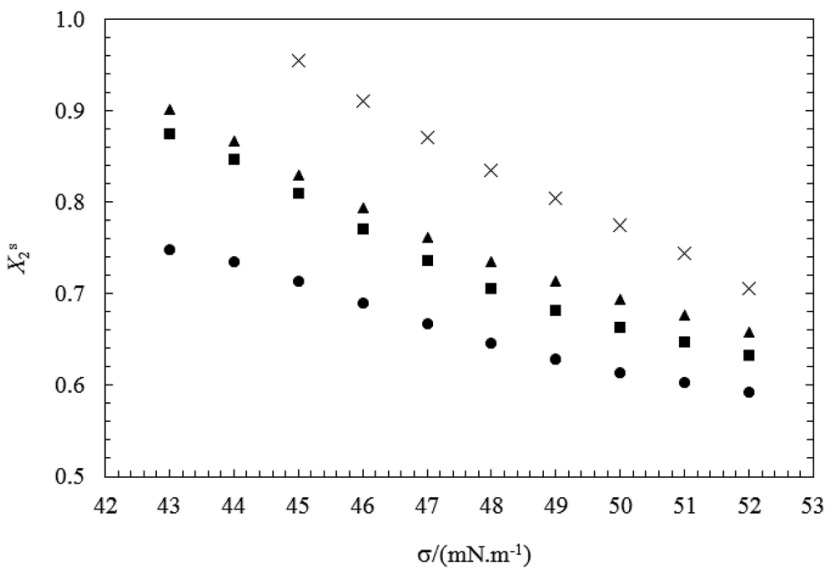

Fig. 3 The mole fraction of $\mathrm{C}_{16} \mathrm{PC}$ at interface $\left(X_{2}^{s}\right)$ versus the surface tension, $\sigma$, for the binary systems of $\mathrm{C}_{16} \mathrm{PC}(2) / \mathrm{TX} 100$ (1) at different bulk mole fraction $\left(y_{1}\right)$ : (O) 0.1093, ( $\left.\mathbf{\square}\right)$ 0.1995, ( $\left.\mathbf{\Delta}\right) 0.3777$ and $(x) 0.5972$.

\subsection{Adsorption of the individual surfactants and their mixture at air-water interface}

The adsorption process involves the transport of molecules from the bulk solution to the interface, where they form specially oriented molecular layers according to the nature of the two phases. The Gibbs adsorption isotherm for multicomponent systems is an equation used to relate the changes in concentration of a component in contact with a surface with changes in the surface tension. For a binary system containing two surfactants, from the Gibbs equation, total adsorption, $\Gamma_{\text {tot }}$, was calculated according to the expression:

$$
\Gamma_{\mathrm{tot}}=-\frac{1}{n R T}\left(\frac{\partial \sigma}{\partial \ln C_{\mathrm{tot}}}\right)_{T, P}
$$

where $\sigma$ and $C_{\text {tot }}$ are the surface tension and the total surfactant concentration in the bulk solution, respectively. For a single surfactant in aqueous solution, $n$ is the number of species formed by way of dissociation of a surfactant molecule. For the binary surfactant mixtures, $n=n_{1} X_{1}^{\mathrm{s}}+n_{2} X_{2}^{\mathrm{s}}$, where $n_{1}$ and $n_{2}$ are

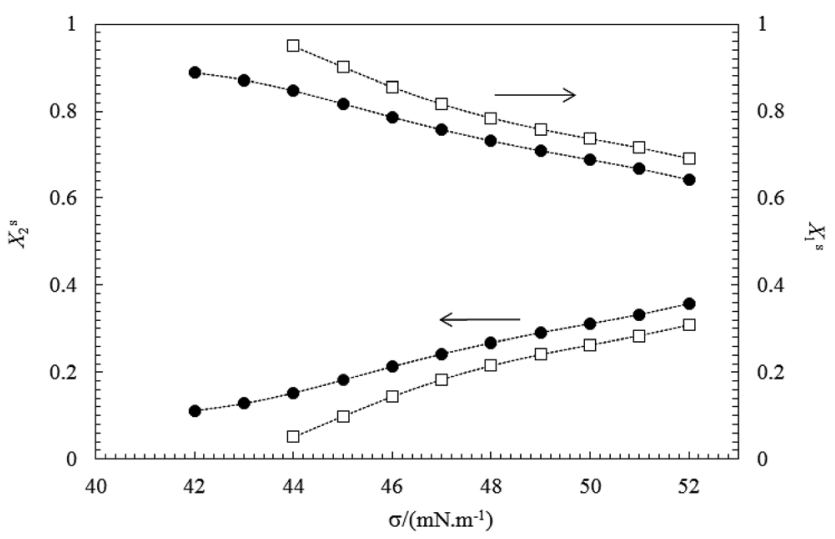

Fig. 4 The mole fractions of TX100 $\left(X_{1}^{s}\right)$ and $C_{n} P C\left(X_{2}^{s}\right)$ at interface versus the surface tension, $\sigma$, for the binary mixtures, at various bulk mole fractions $\left(y_{1}\right): C_{14} P C(2) / T X 100(1)$ mixture at $y_{1}=0.2948$ (open square) and $C_{16} P C(2) / T X 100(1)$ mixture at $y_{1}=0.2901$ (closed circle). The continuous dashed curve is a guide for the eyes.

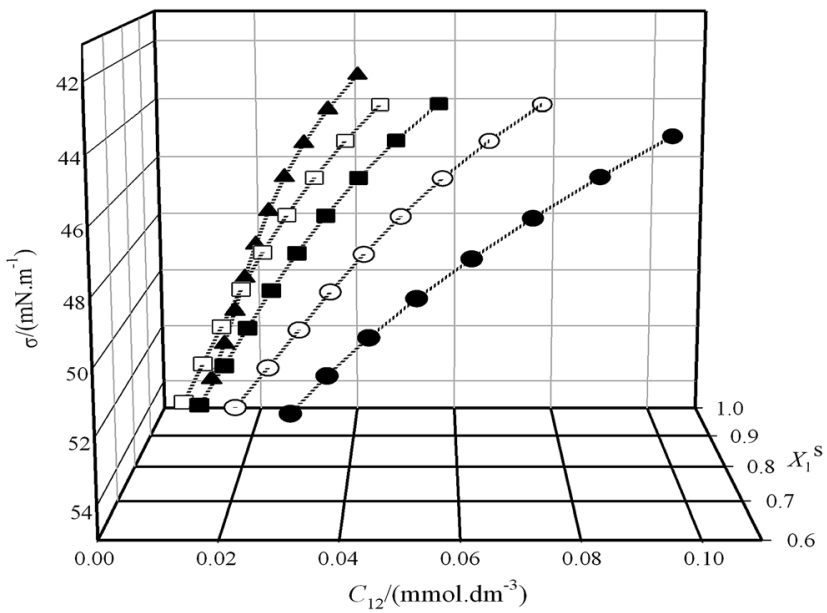

Fig. 5 The values of surface tension, $\sigma$, against $C_{12}$ and $X_{1}^{\mathrm{s}}$ for $C_{14} \mathrm{PC}(2) /$ TX100(1) mixture at various bulk mole fractions $\left(y_{1}\right)$ : (O) $0.1999,(O)$ 0.2948, ( $\boldsymbol{\square}$ ) 0.4022, ( $\square$ ) 0.4986 and ( $\boldsymbol{\Delta}$ ) 0.6009. The symbols were calculated using the data and the continuous dashed curve is a guide for the eyes.

the number of species of surfactant 1 and 2, respectively, whose interfacial concentration changes with the change in surfactant bulk concentration; $X_{i}^{\mathrm{s}}$ is the mole fraction of the $i$ th surfactant in the mixed monolayer. The results in this work show that the value of $n$ is almost 1 in most of the mole fractions. ${ }^{\mathbf{1 4 2 6}}$

The data between $\sigma$ and $\log C_{\text {tot }}$ were fitted by a second-order polynomial equation, then from the differentiation of this equation, the total adsorption values $\left(\Gamma_{\text {tot }}\right)$ were calculated at various fixed surface tension (for each $C_{\text {tot }}$ value). Then the average surface area per molecule of surfactants $\left(A_{\text {tot }}\right)$ at the interface was obtained from the relation:

$$
A_{\text {tot }}=\frac{10^{20}}{N_{\mathrm{A}} \Gamma_{\text {tot }}}\left(\AA^{2} \text { per molecule }\right)
$$

where $N_{\mathrm{A}}$ is the Avogadro number.

The total adsorption values $\left(\Gamma_{\text {tot }}\right)$ and the mole fraction of surfactant $i$ th in the mixed monolayer $\left(X_{i}^{s}\right)$ (as described above section) can be used to find out the adsorbed amount of the individual surfactant in the mixed monolayer $\left(\Gamma_{\mathrm{TX} 100}\right.$ and $\left.\Gamma_{\mathrm{C}_{n} \mathrm{PC}}\right)^{27}$

$$
\begin{aligned}
& \Gamma_{1}=X_{1}^{\mathrm{s}} \Gamma_{\text {tot }} \\
& \Gamma_{2}=X_{2}^{\mathrm{s}} \Gamma_{\text {tot }}
\end{aligned}
$$

Surfactant 1 always refers to TX100 and surfactant 2 refers to $\mathrm{C}_{n} \mathrm{PC}$ in binary mixtures.

\section{Results and discussion}

Fig. 1(a and b) show plots of surface tension $\sigma$ as a function of the total surfactant concentration $C\left(\log C_{\text {tot }}\right)$ for the pure $\mathrm{C}_{n} \mathrm{PC}$, the pure TX100 and for two surfactant mixtures at bulk mole fraction range of $\left(y_{1} \approx 0.1-0.6\right)$ with an interval of almost 0.1. The surfactant molecules have the tendency to adsorb to fluid interface in which the hydrophilic parts are attached to the 


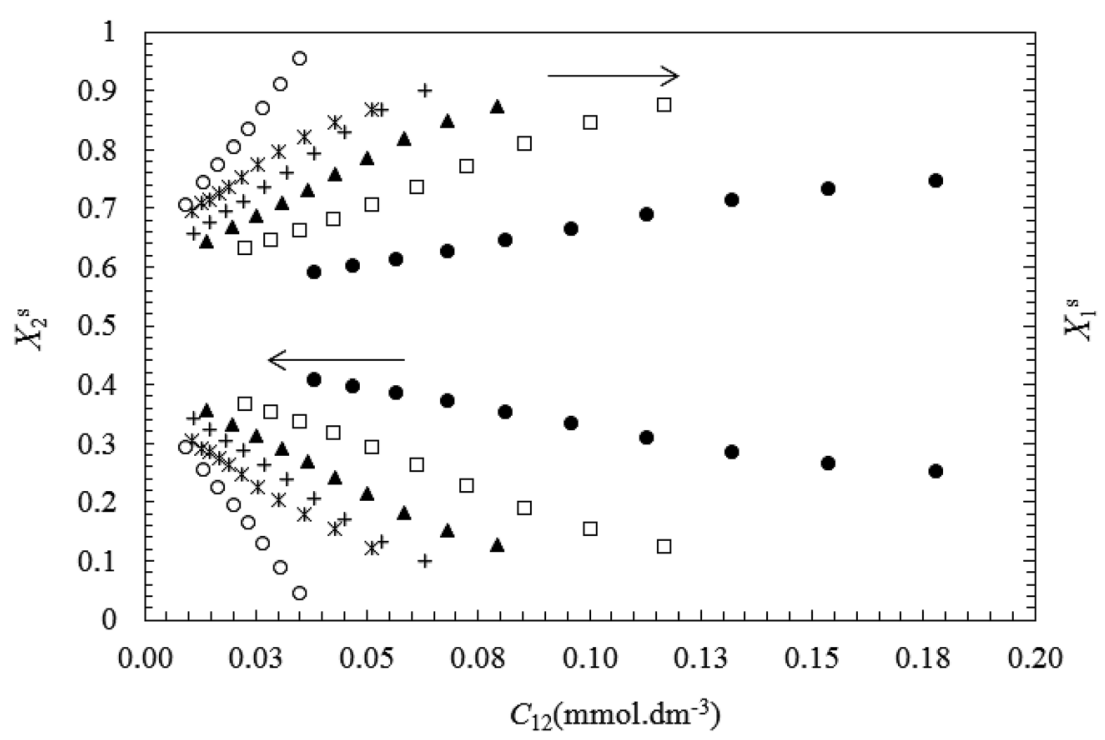

Fig. 6 The mole fractions of TX100 $\left(X_{1}^{s}\right)$ and $C_{16} \mathrm{PC}\left(X_{2}^{s}\right)$ at interface vs. the total surfactant concentrations in pre-micellar region, $C_{12}$, at various bulk mole fractions $\left(y_{1}\right)$ : (O) 0.1093, ( $\square$ ) 0.1995, ( $\left.\mathbf{\Delta}\right) 0.2901,(+) 0.3777$ (*) 0.5001 and (O) 0.5972 .

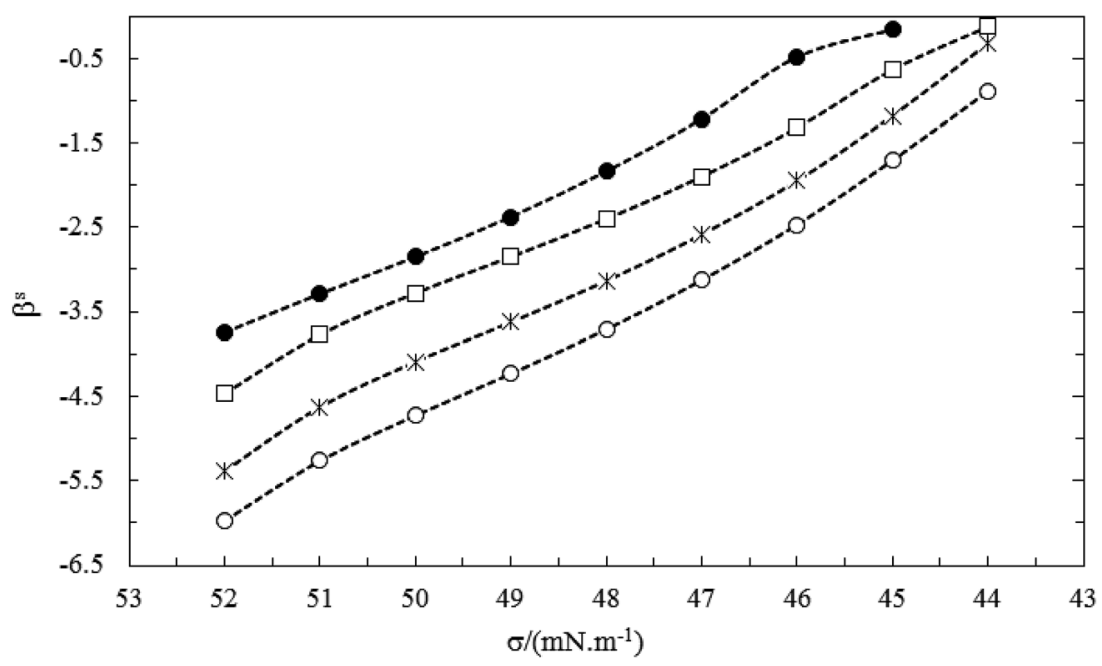

Fig. 7 The interaction parameter at interface $\left(\beta^{\mathrm{s}}\right)$ vs. surface tension of mixture for the $\mathrm{C}_{14} \mathrm{PC}(2) / \mathrm{TX} 100(1)$ system at various mole fractions of $y_{1}$ : (•) 0.1999, ( $\square$ ) 0.2948, (*) 0.4022 and (O) 0.4986. The continuous dashed curves are guide to the eyes.

surface and hydrophobic parts are oriented in parallel (not parallel) position, this structure decrease the interaction between water molecules in interface which consequently decreases the surface tension values. ${ }^{24}$

At very low concentrations of the surfactant, only monomers are present in bulk solution and interface. As the concentration of the surfactant is increased, the surface tension at the airliquid interface is lowered until the solution critical micelle concentration (CMC) is reached. After the CMC is reached, the surface tension at the air-liquid interface typically remains constant.

Any further increase in concentration does not change the surface tension $\left(C_{\mathrm{t}} \geq \mathrm{CMC}\right)$. The CMC is indicated by a sharp break in all curves. These plots were used to determine the $C_{1}$, $C_{2}, C_{12}$ at $C_{\mathrm{t}} \leq \mathrm{CMC}$ and CMC values. In this study, for the calculation of $C_{1}, C_{2}$ and $C_{12}$ were used the various fixed values of surface tension in pre-micellar region (see Fig. 2) and then, the influence of surface tension on the surface properties is investigated.

The data $\left(\sigma-C_{i}\right)$ in Fig. 1(a and b) doesn't exactly support the concentrations $\left(C_{1}, C_{2}\right.$ and $\left.C_{12}\right)$ at $\sigma=43,44, \ldots 52 \mathrm{mN} \mathrm{m}^{-1}$, therefore, the experimental data $\left(\sigma-C_{i}\right)$ were fitted with a second-order equation to obtain the required concentrations $\left(C_{1}, C_{2}\right.$ and $\left.C_{12}\right)$ for eqn (1) and (2).

In Table 1 , the obtained $C_{1}$ (the molar concentrations of $\mathrm{C}_{n} \mathrm{PC}$ ) and $C_{2}$ (the molar concentrations of TX100) values are listed from correlation between $\sigma$ and $\log C_{i}$ at any given surface tension value in pre-micellar region for three individual surfactant. Also, Table 2 summarized the surface properties $\left(\beta^{\mathrm{s}}\right.$, $X_{i}^{\mathrm{s}}, \Gamma_{\mathrm{tot}}, A_{\mathrm{tot}}, \Gamma_{\mathrm{TX} 100}$ and $\left.\Gamma_{\mathrm{C}_{n} \mathrm{PC}}\right)$ that obtained at different mole fraction of surfactant in the bulk solution. 


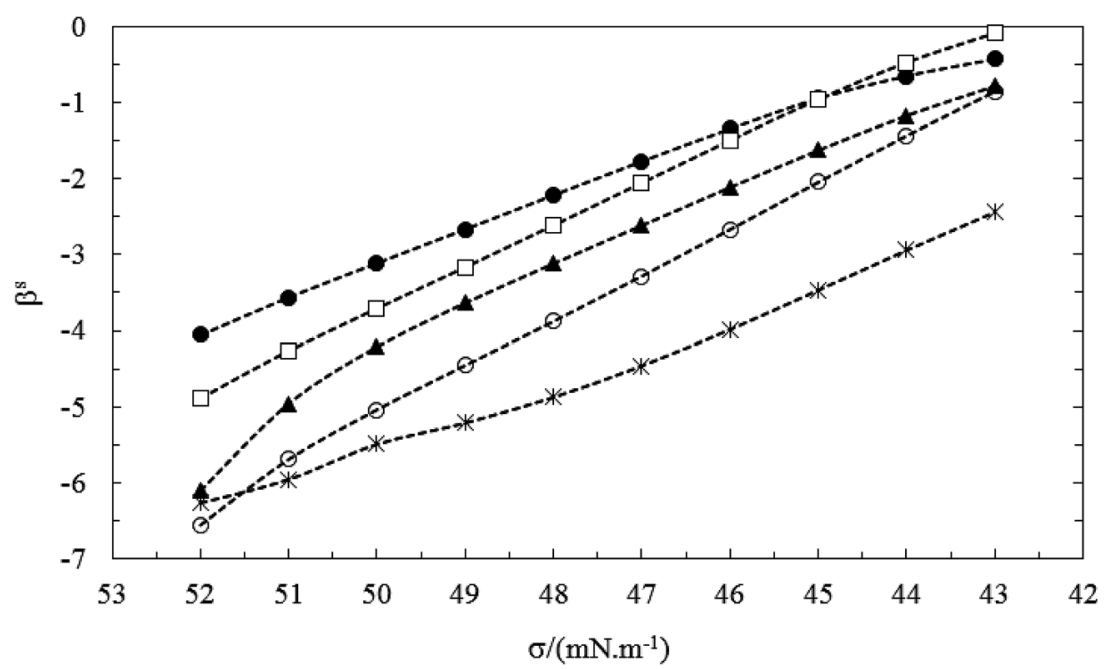

Fig. 8 The interaction parameter at interface $\left(\beta^{\mathrm{s}}\right)$ vs. surface tension of mixture for the $\mathrm{C}_{16} \mathrm{PC}(2) / \mathrm{TX} 100(1)$ system at various mole fractions of $y_{1}$ : ( ) 0.1093, ( $\square$ ) 0.1995, ( $\mathbf{\Delta})$ 0.2901, (O) 0.3777 and (*) 0.5001. The continuous dashed curves are guide to the eyes.

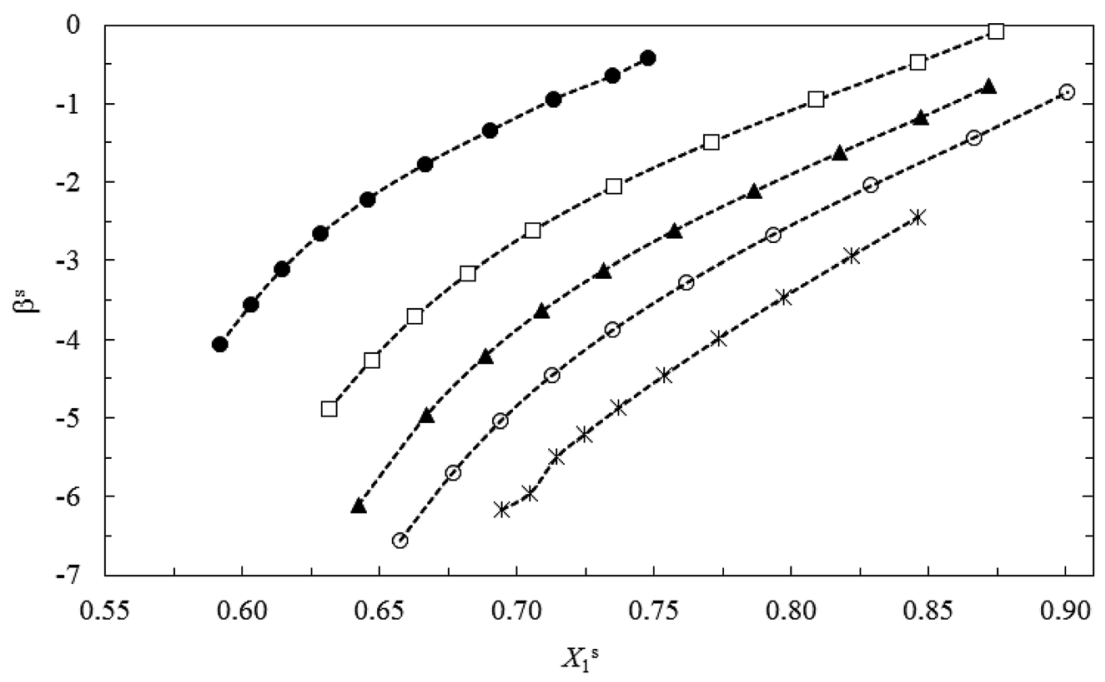

Fig. 9 The interaction parameter at interface $\left(\beta^{\mathrm{s}}\right)$ vs. the mole fraction of TX100 at interface $\left(X_{1}^{s}\right)$ for the $C_{16} \mathrm{PC}(2) / \mathrm{TX} 100(1)$ system at various mole fractions of $y_{1}:(\mathbf{O})$ 0.1093, $(\square)$ 0.1995, ( $\mathbf{\Delta}$ ) 0.2901, (O) 0.3777 and $(*)$ 0.5001. The continuous dashed curves are guide to the eyes.

The obtained results show that $X_{1}^{s}$ value increase and $X_{2}^{\mathrm{s}}$ value decrease with decreasing the surface tension mixture at each bulk mole fraction $\left(y_{1}\right)$.

This indicates the formation of interface in surfactant mixtures, the component with the lower CMC is usually dominant at the air-water interface due to its higher surface activity. The above results are in accordance with the fact that TX100 is much more surface active than $\mathrm{C}_{n} \mathrm{PC}$ (see Fig. 3 and 4).

The changes in $X_{1}^{s}$ and $X_{2}^{s}$ with increasing total concentration $\left(C_{12}\right)$ of the mixed surfactants (or with decreasing $\sigma$ values) are shown in Fig. 5 and 6. These figures show that the mole fraction of TX100 $\left(X_{1}^{s}\right)$ increases and the corresponding the mole fraction of $\mathrm{C}_{n} \mathrm{PC}\left(X_{2}^{S}\right)$ at the air-water interface decreases continuously as a function of the total concentration (or surface tension). This indicates that $\mathrm{C}_{n} \mathrm{PC}$ molecules present at the original interface are continuously being displaced by TX100 molecules, due to the higher tendency of TX100 to surface.

In order to gain further information about the nature and strength of the interaction among the two surfactants at the surface, we evaluated the interaction parameter for mixed monolayer formation $\left(\beta^{\mathrm{s}}\right)$ at various surface tension.

The $\beta^{\mathrm{s}}$ values are always negative in both systems (see Table 2 ). This indicates that the interactions between the two different surfactants after mixing (TX100 and $\mathrm{C}_{n} \mathrm{PC}$ ) are more attractive or less repulsive than before mixing. Before mixing, the ionic surfactant, $\mathrm{C}_{n} \mathrm{PC}$, has a strong electrostatic self-repulsion, the nonionic surfactant, TX100, has a steric self-repulsion. After mixing, both of these interactions are weakened by a dilution effect. On the other hand, an ion-dipole attractive interaction and Van der Waals attraction (between the hydrophilic groups) are formed between cationic-nonionic surfactants after mixing 


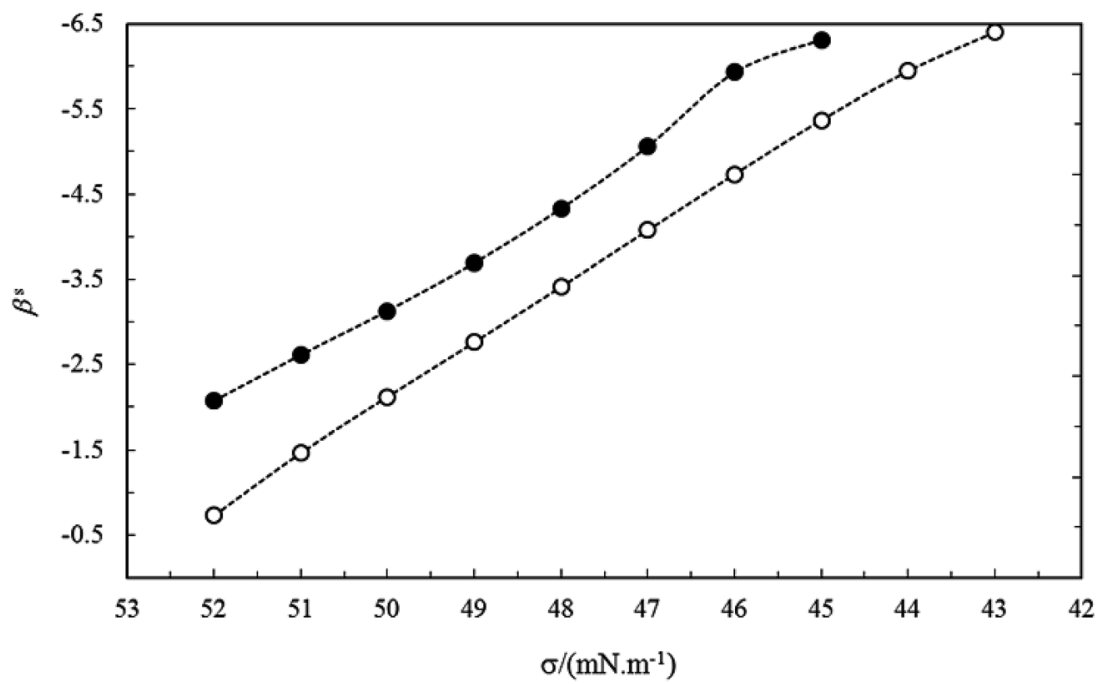

Fig. 10 The interaction parameter at interface $\left(\beta^{s}\right)$ vs. surface tension of mixture for the $\mathrm{C}_{n} \mathrm{PC}(2) / \mathrm{TX} 100(1)$ systems with the same mole fractions $\left(y_{1}=0.199\right):(0) C_{14} P C$ and $(O) C_{16} P C$.

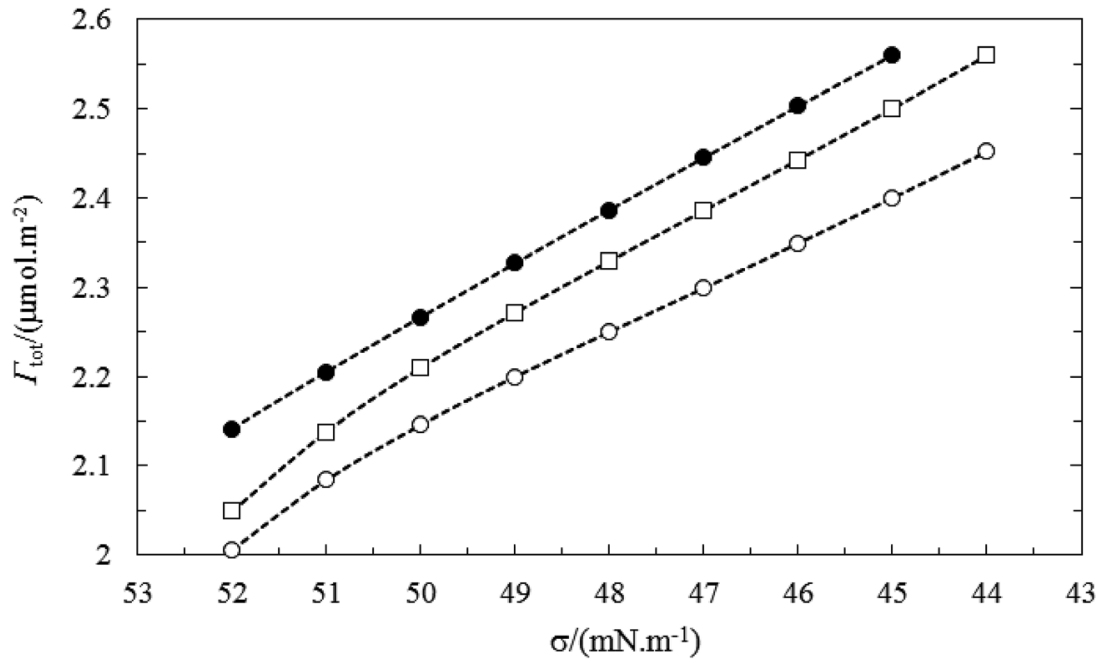

Fig. 11 A typical plot of the values of the total surfactant adsorption vs. surface tension of mixture for the $C_{14} P C(2) / T X-100(1)$ mixture at various mole fractions of $y_{1}:(\mathbf{O}) 0.1999,(\square) 0.2948$ and $(O)$ 0.4022. The continuous dashed curves are guide to the eyes.

of the two components. ${ }^{13,14}$ In the studied systems at all the bulk mole fractions $\left(y_{1}\right)$, the $\beta^{\mathrm{s}}$ values decreased (less negative) with decrease of the surface tension at before CMC due to reduction of the mole fraction of $\mathrm{C}_{n} \mathrm{PC}$ at the air-water interface $\left(X_{2}^{s}\right)$ or increase of the mole fraction of TX100 at the air-water interface $\left(X_{1}^{S}\right)$. In fact, the reduction of $\mathrm{C}_{n} \mathrm{PC}$ molecules and increase of TX100 molecules at interface decreased the electrostatic selfrepulsion interaction between two molecules of $\mathrm{C}_{n} \mathrm{PC}$ at interface upon mixing (see Fig. 7-9).

In the same bulk mole fraction of two studied systems (for example $y_{1} \approx 0.199$ ), the mean values of $\beta^{\mathrm{s}}\left(\bar{\beta}^{\mathrm{s}}\right)$ for $\mathrm{C}_{16} \mathrm{PC} / \mathrm{TX} 100$ system is more negative than $\mathrm{C}_{14} \mathrm{PC} / \mathrm{TX} 100$ system. The larger values of $\bar{\beta}^{\mathrm{s}}$ for the $\mathrm{C}_{16} \mathrm{PC} / \mathrm{TX} 100$ system can be ascribed to the larger Van der Waals force between the longer lipophilic groups of this system after mixing and more presence of $\mathrm{C}_{16} \mathrm{PC}$ at interface, compared to the $\mathrm{C}_{14} \mathrm{PC} / \mathrm{TX} 100$ system (see Fig. 10).

From another point of view, the electrostatic self-repulsion interactions between ionic surfactants decrease with increasing the hydrophilic group of the ionic surfactant in cationic-nonionic surfactant mixtures.

The above results are in accordance with the fact that TX100 is much more surface active than $\mathrm{C}_{n} \mathrm{PC}$. The total adsorbed amount of the mixture $\left(\Gamma_{\text {tot }}\right)$ at the air-water surface can be calculated using the eqn (3). Fig. 11 and 12 show the behavior of total adsorption with surface tension, typically. For all the systems studied the total adsorption $\left(\Gamma_{\text {tot }}\right)$ increase with the decrease of surface tension and finally reaches a maximum value of the saturated surface adsorption (almost in CMC 


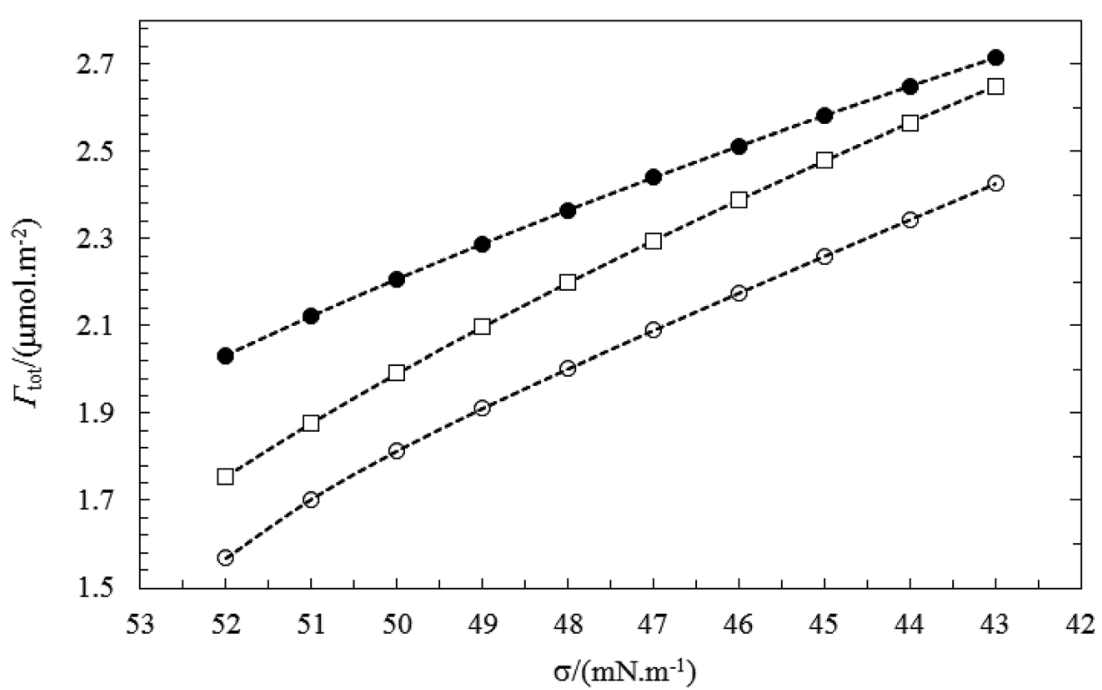

Fig. 12 A typical plot of the values of the total surfactant adsorption vs. surface tension of mixture for the $\mathrm{C}_{16} \mathrm{PC}(2) / \mathrm{TX}-100(1)$ mixture at various mole fractions of $y_{1}:(0) 0.1093,(\square) 0.1995$ and $(O) 0.3777$. The continuous dashed curves are guide to the eyes.

point). Also, the results of Table 3 show the $\Gamma_{\text {tot }}$ value increases gradually with increasing the total concentration of surfactant.

In order to determine the surfactant composition at the surface $\left(\Gamma_{1}, \Gamma_{2}\right)$ were used eqn (5) and (6). Fig. 13 and 14 show plots of total adsorption $\left(\Gamma_{\text {tot }}\right)$, the adsorbed amount of $\mathrm{C}_{n} \mathrm{PC}$ $\left(\Gamma_{\mathrm{C}_{n} \mathrm{PC}}\right)$ and TX100 $\left(\Gamma_{\mathrm{TX100}}\right)$ at the surface as a function of the total surfactant concentration $\left(C_{\text {tot }}\right)$ in pre-micellar region, typically. The variation of adsorption $\left(\Gamma_{\text {tot }}, \Gamma_{1}\right.$ and $\left.\Gamma_{2}\right)$ with composition follows distinctively same patterns at various mole fractions. Fig. 13 and 14 show that the adsorbed amount of TX100 $\left(\Gamma_{\text {TX-100 }}\right)$ increases and the corresponding amount of $\mathrm{C}_{n} \mathrm{PC}\left(\Gamma_{\mathrm{C}_{n} \mathrm{PC}}\right)$ adsorbed at the surface decreases continuously as a function of the total surfactant concentration. This indicates that $\mathrm{C}_{n} \mathrm{PC}$ molecules (a surfactant with a larger polar head group) present at the original surface are continuously being displaced by TX100 molecules, due to the higher surface activity of TX100.

The values of $A_{\text {tot }}$ and surface coverage $\left(=A_{\text {tot }} / A_{\text {min }}\right)$ of mixture in the binary system at various surface tension can be calculated according to eqn (4) using the total surfactant adsorption $\left(\Gamma_{\text {tot }}\right)$ (see Table 3 ).

As Table 3 show, the values of $A_{\text {tot }}$ for binary mixtures decrease with decreasing surface tension (or increasing the mole fraction of TX100 at the air-water interface $\left(X_{1}^{\mathrm{s}}\right)$ ).

In the high surface tension (at low concentration of nonionic surfactant), the mean area occupied by each molecule at the interface $\left(A_{\text {tot }}\right)$ is very high due to the electrostatic selfrepulsion between head groups of the cationic surfactants, and then with decreasing of surface tension the value of $A_{\text {tot }}$ decreases.

By considering that the surface tension value decreases with the increase of total concentration of surfactant, while the values of $A_{\text {tot }}$ decreases with increasing of $X_{1}^{\mathrm{s}}$. This can be attributed to the following reasons: (i) the decrease in selfrepulsion of the cationic surfactants (or the population of $\mathrm{C}_{14} \mathrm{PC}$ or $\mathrm{C}_{14} \mathrm{PC}$ components at the interface decreases), (ii) the decrease in steric self-repulsion of the nonionic upon mixing, due to the dilution effect mentioned previously.

The alkyl chain length also plays an important role on $A_{\text {tot }}$ values. Short chain length of $\mathrm{C}_{14} \mathrm{PC}$ occupies smaller $A_{\text {tot }}$ than $\mathrm{C}_{16} \mathrm{PC}$ chains do at the interface, which is due to accompanied by higher population (see results in the same bulk mole fraction of cationic surfactant: $y_{1} \approx 0.199$ ).

\section{Conclusion}

In this work, surface properties of binary mixtures of the two cationic surfactants (alkyl pyridinium chlorides: $\mathrm{C}_{14} \mathrm{PC}$ and $\mathrm{C}_{16} \mathrm{PC}$ ) with the non-ionic surfactant Triton X-100 (TX100) have been studied at different total mole fractions in pre-micellar region. The interaction parameters $\left(\beta^{\mathrm{s}}\right)$ and the mole fractions of the surfactants in the mixed monolayer $\left(X_{i}^{S}\right)$ were calculated using regular solution theory (Rosen theory) at various fixed values of surface tension.

The values of $X_{1}^{\mathrm{s}}$ and $X_{2}^{\mathrm{s}}$ calculated by this model show higher contribution of TX100 $\left(X_{1}^{s}\right)$ in the mixed monolayers. Results showed that the hydrophobic chain length of the cationic surfactant and the initial total mole fraction in the mixed solutions affect their partitioning in the adsorbed mixed monolayers. The value of $\beta^{\mathrm{s}}$ reflects the molecular interaction parameter for mixed monolayers.

Negative values of $\beta^{\mathrm{s}}$ parameter were obtained for both $\mathrm{C}_{14} \mathrm{PC}-\mathrm{TX} 100$ and $\mathrm{C}_{16} \mathrm{PC}-\mathrm{TX} 100$ mixed monolayers, this indicates that synergism take place in the mixing process. Dilution effect upon mixing and a large number of attractive Van der Waals interactions between neighboring hydrophobic parts for $\mathrm{C}_{n} \mathrm{PC} / \mathrm{TX} 100$ mixtures is proposed as a major factor to the negative $\beta^{\mathrm{s}}$ values observed for mixed monolayers. Also, the interaction in the mixed monolayer at the air-water interface (the $\beta^{\text {s }}$ values become more negatives) is increased with increasing in the hydrophobic group in ionic surfactant of the mixture. Moreover, it can be seen that the values of $A_{\text {tot }}$ and 
Table $3 \quad C_{12}$ is the molar concentration of surfactant mixture at various fixed values of surface tension $(\sigma)$ in pre-micellar region, $X_{1}^{s}$ (the mole fraction of TX100) and $X_{2}^{s}$ (the mole fraction of $C_{16} \mathrm{PC}$ ) in interface, $\Gamma_{\text {tot, }} \Gamma_{1}$ and $\Gamma_{2}$ are the total surfactant adsorption, the TX100 adsorption and the $\mathrm{C}_{16} \mathrm{PC}$ adsorption respectively, and $A_{\text {tot }}$ is the average surface area per molecule of components

\begin{tabular}{|c|c|c|c|c|c|c|c|c|}
\hline$\sigma /\left(\mathrm{mN} \mathrm{m}^{-1}\right)$ & $C_{12} /\left(\mathrm{mmol} \mathrm{dm}^{-3}\right)$ & $X_{1}^{s}$ & $X_{2}^{s}$ & $\beta^{\mathrm{s}}$ & $\Gamma_{\text {tot }} /\left(\mu \mathrm{mol} \mathrm{m}^{-2}\right)$ & $A_{\text {tot }} /\left(\AA^{2}\right)$ & Surface coverage & $\Gamma_{1} /\left(\mu \mathrm{mol} \mathrm{m}^{-2}\right)$ \\
\hline
\end{tabular}

For $\mathrm{C}_{16} \mathrm{PC}(2) / \mathrm{TX100}(1)$ at $y_{1}=0.1093$

$\begin{array}{llllll}52 & 0.0382 & 0.5920 & 0.4080 & -4.06 & 2.033 \\ 51 & 0.0467 & 0.6030 & 0.3970 & -3.56 & 2.122 \\ 50 & 0.0566 & 0.6144 & 0.3856 & -3.11 & 2.207 \\ 49 & 0.0679 & 0.6283 & 0.3717 & -2.66 & 2.288 \\ 48 & 0.0809 & 0.6456 & 0.3544 & -2.22 & 2.365 \\ 47 & 0.0958 & 0.6665 & 0.3335 & -1.77 & 2.440 \\ 46 & 0.1127 & 0.6902 & 0.3098 & -1.34 & 2.512 \\ 45 & 0.1318 & 0.7135 & 0.2865 & -0.94 & 2.581 \\ 44 & 0.1535 & 0.7347 & 0.2653 & -0.65 & 2.649 \\ 43 & 0.1777 & 0.7476 & 0.2524 & -0.43 & 2.714\end{array}$

For $\mathrm{C}_{16} \mathrm{PC}(2) / \mathrm{TX100}(1)$ at $y_{1}=0.1995$

$\begin{array}{llllll}52 & 0.0226 & 0.6318 & 0.3682 & -4.88 & 1.755 \\ 51 & 0.0283 & 0.6471 & 0.3529 & -4.26 & 1.878 \\ 50 & 0.0349 & 0.6631 & 0.3369 & -3.71 & 1.991 \\ 49 & 0.0424 & 0.6822 & 0.3178 & -3.16 & 2.097 \\ 48 & 0.0511 & 0.7061 & 0.2939 & -2.61 & 2.198 \\ 47 & 0.0611 & 0.7356 & 0.2644 & -2.05 & 2.295 \\ 46 & 0.0725 & 0.7706 & 0.2294 & -1.49 & 2.389 \\ 45 & 0.0855 & 0.8092 & 0.1908 & -0.96 & 2.478 \\ 44 & 0.1003 & 0.8463 & 0.1537 & -0.47 & 2.565 \\ 43 & 0.1169 & 0.8746 & 0.1254 & -0.08 & 2.648\end{array}$

For $\mathrm{C}_{16} \mathrm{PC}(2) / \mathrm{TX100}(1)$ at $y_{1}=0.2901$

$\begin{array}{llllll}52 & 0.0140 & 0.6422 & 0.3578 & -6.11 & 1.721 \\ 51 & 0.0197 & 0.6673 & 0.3327 & -4.96 & 1.868 \\ 50 & 0.0252 & 0.6885 & 0.3115 & -4.21 & 1.973 \\ 49 & 0.0307 & 0.7091 & 0.2909 & -3.63 & 2.057 \\ 48 & 0.0365 & 0.7317 & 0.2683 & -3.12 & 2.131 \\ 47 & 0.0428 & 0.7575 & 0.2425 & -2.61 & 2.200 \\ 46 & 0.0500 & 0.7865 & 0.2135 & -2.11 & 2.267 \\ 45 & 0.0583 & 0.8174 & 0.1826 & -1.62 & 2.333 \\ 44 & 0.0679 & 0.8473 & 0.1527 & -1.17 & 2.398 \\ 43 & 0.0792 & 0.8719 & 0.1281 & -0.78 & 2.465\end{array}$

For $\mathrm{C}_{16} \mathrm{PC}(2) / \mathrm{TX100}(1)$ at $y_{1}=0.3777$

$\begin{array}{llllll}52 & 0.0140 & 0.0112 & 0.6575 & -6.56 & 1.567 \\ 51 & 0.0197 & 0.0147 & 0.6767 & -5.69 & 1.703 \\ 50 & 0.0252 & 0.0183 & 0.6942 & -5.04 & 1.813 \\ 49 & 0.0307 & 0.0223 & 0.7129 & -4.45 & 1.911 \\ 48 & 0.0365 & 0.0268 & 0.7351 & -3.88 & 2.001 \\ 47 & 0.0428 & 0.0320 & 0.7617 & -3.28 & 2.089 \\ 46 & 0.0500 & 0.0380 & 0.7933 & -2.67 & 2.174 \\ 45 & 0.0583 & 0.0451 & 0.8290 & -2.04 & 2.259 \\ 44 & 0.0679 & 0.0534 & 0.8663 & -1.43 & 2.343 \\ 43 & 0.0792 & 0.0631 & 0.9006 & -0.86 & 2.425\end{array}$

For $\mathrm{C}_{16} \mathrm{PC}(2) / \mathrm{TX100}(1)$ at $y_{1}=0.5001$

$\begin{array}{llllll}52 & 0.0108 & 0.6943 & 0.3057 & -6.17 & 2.219 \\ 51 & 0.0127 & 0.7090 & 0.2910 & -5.95 & 2.236 \\ 50 & 0.0146 & 0.7146 & 0.2854 & -5.49 & 2.250 \\ 49 & 0.0167 & 0.7245 & 0.2755 & -5.21 & 2.263 \\ 48 & 0.0191 & 0.7372 & 0.2628 & -4.87 & 2.277 \\ 47 & 0.0220 & 0.7536 & 0.2464 & -4.46 & 2.291 \\ 46 & 0.0256 & 0.7737 & 0.2263 & -3.98 & 2.307 \\ 45 & 0.0302 & 0.7970 & 0.2030 & -3.47 & 2.323 \\ 44 & 0.0358 & 0.8218 & 0.1782 & -2.94 & 2.340 \\ 43 & 0.0427 & 0.8463 & 0.1537 & -2.44 & 2.358\end{array}$

For $\mathrm{C}_{16} \mathrm{PC}(2) / \mathrm{TX100}(1)$ at $y_{1}=0.5973$

$\begin{array}{llll}81.73 & 0.70 & 1.203 & 0.829 \\ 78.27 & 0.73 & 1.280 & 0.843 \\ 75.27 & 0.76 & 1.356 & 0.851 \\ 72.61 & 0.79 & 1.437 & 0.851 \\ 70.23 & 0.81 & 1.527 & 0.838 \\ 68.08 & 0.84 & 1.626 & 0.814 \\ 66.13 & 0.87 & 1.734 & 0.778 \\ 64.35 & 0.89 & 1.842 & 0.740 \\ 62.72 & 0.91 & 1.946 & 0.703 \\ 61.22 & 0.93 & 2.029 & 0.685\end{array}$

$94.67 \quad 0.60$

$88.48 \quad 0.61$

$83.44 \quad 0.68$

$79.21 \quad 0.71$

$75.56 \quad 0.75$

$72.37 \quad 0.78$

$69.55 \quad 0.81$

$67.03 \quad 0.84$

$64.76 \quad 0.87$

$62.72 \quad 0.90$

1.109

1.215

1.320

1.431

1.552

1.688

1.841

2.005

2.171

2.316

0.646

0.663

0.671

0.667

0.646

0.607

0.548

0.473

0.394

0.332

\section{$96.52 \quad 0.63$}

$88.93 \quad 0.68$

$84.20 \quad 0.72$

$80.74 \quad 0.75$

$77.94 \quad 0.78$

$75.50 \quad 0.80$

$73.28 \quad 0.82$

$71.21 \quad 0.85$

$69.26 \quad 0.87$

$67.40 \quad 0.90$

1.105

1.247

1.358

1.459

1.560

1.670

1.783

1.907

2.032

2.149

0.616

0.621

0.615

0.598

0.572

0.534

0.484

0.426

0.366

0.316

$106.0 \quad 0.55$

$97.56 \quad 0.60$

$91.62 \quad 0.64$

$86.95 \quad 0.67$

$83.00 \quad 0.70$

$79.53 \quad 0.73$

$76.40 \quad 0.76$

$73.54 \quad 0.79$

$70.91 \quad 0.82$

$68.49 \quad 0.85$

1.030

0.537

1.152

1.259

0.550

1.362

1.471

1.591

1.725

1.873

2.030

2.184

0.555

0.548

0.530

0.498

0.449

0.386

0.313

0.241

$\begin{array}{ll}74.85 & 0.90 \\ 74.30 & 0.90 \\ 73.83 & 0.91 \\ 73.40 & 0.91 \\ 72.96 & 0.92 \\ 72.50 & 0.93 \\ 72.02 & 0.94 \\ 71.51 & 0.94 \\ 70.98 & 0.95 \\ 70.44 & 0.96\end{array}$

1.541

0.679

$1.585 \quad 0.651$

$1.608 \quad 0.642$

$1.640 \quad 0.624$

$1.678 \quad 0.598$

$1.727 \quad 0.565$

$1.785 \quad 0.522$

$1.851 \quad 0.472$

$1.923 \quad 0.417$

$1.996 \quad 0.363$ 
Table 3 (Contd.)

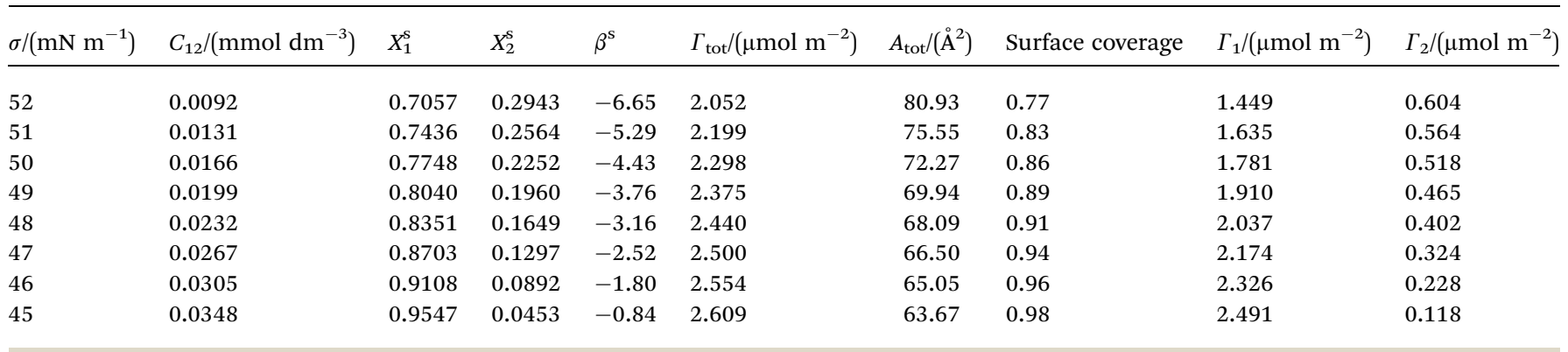

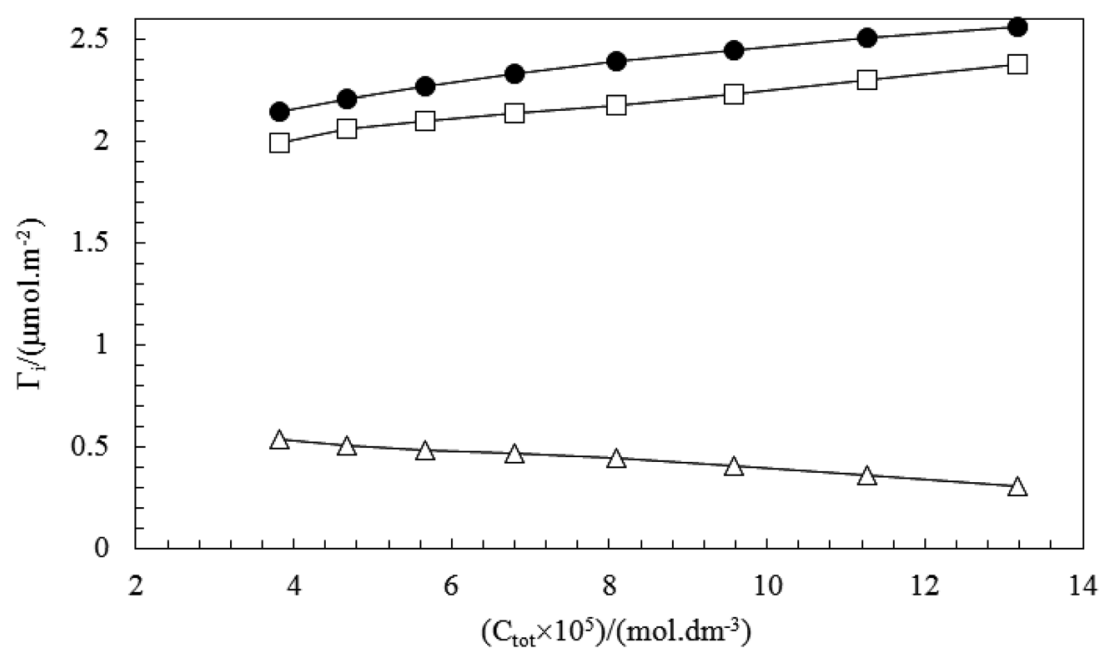

Fig. 13 Variation of the total adsorption $\left(\Gamma_{\text {tot }}\right)$, the adsorbed amount of TX100 $\left(\Gamma_{\mathrm{TX100}}\right)$ and the adsorbed amount of $\mathrm{C}_{14} \mathrm{PC}\left(\Gamma_{\mathrm{C}_{14} \mathrm{PC}}\right)$ as a function of the total surfactant concentration at $y_{1}=0.1995:(\square)$ TX-100, $(\Delta) \mathrm{C}_{14} \mathrm{PC}$ and $(\mathbf{O}) \Gamma_{\text {tot }}$. The solid curves are guide to the eyes.

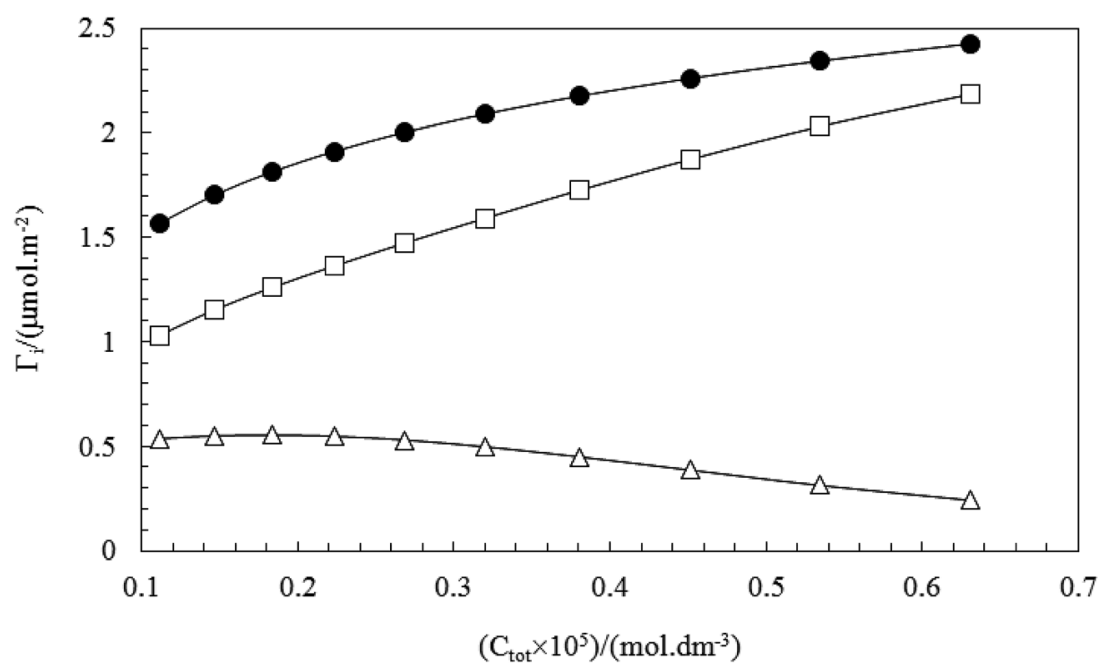

Fig. 14 Variation of the total adsorption $\left(\Gamma_{\text {tot }}\right)$, the adsorbed amount of TX100 $\left(\Gamma_{\mathrm{TX100}}\right)$ and the adsorbed amount of $\mathrm{C}_{16} \mathrm{PC}\left(\Gamma_{\mathrm{C}_{16} \mathrm{PC}}\right)$ as a function of the total surfactant concentration at $y_{1}=0.3777$ : $(\square)$ TX-100, ( $\left.\Delta\right)$ C16PC and $(0) \Gamma_{\text {tot. }}$ The solid curves are guide to the eyes.

surface coverage will decrease with decreasing surface tension and increasing the mole fraction of non-ionic surfactant at the air-water interface $\left(X_{1}^{s}\right)$. Finally, these studies show that the surface parameters $\left(\beta^{\mathrm{s}}, X_{i}^{\mathrm{s}}\right.$ and $e t c$. $)$ are very dependent on the values of the selected fixed surface tension (in the curves of pure and surfactant mixtures) for the calculation of $C_{1}, C_{2}$ and $C_{12}$ at pre-micellar region. This effect has not been previously reported in many papers related to mixed surfactants studies. 


\section{Acknowledgements}

We gratefully acknowledge the financial support received for this research work from the Research Council of Semnan University.

\section{References}

1 R. Sharma and R. Kumar Mahajan, RSC Adv., 2012, 2, 95719583.

2 N. Ranjan Biswal and S. Paria, RSC Adv., 2014, 4, 9182-9188.

3 W. V. Rybinski and M. J. Schwuger, Langmuir, 1986, 2, 639643.

4 P. Posocco, A. Perazzo, V. Preziosi, E. Laurini, S. Pricl and S. Guido, RSC Adv., 2016, 6, 4723-4729.

5 A. Bera, K. Ojha and A. Mandal, J. Surfactants Deterg., 2013, 16, 621-630.

6 M. J. Rosen, Molecular interaction and synergism in binary mixtures of surfactants, ACS symposium series 311, American Chemical Society, Washington, DC, 1986.

7 P. M. Holland and D. N. Rubingh, Mixed surfactants systems, ACS symposium series 50, American Chemical Society, Washington DC, 1992, ch. 1.

8 D. E. Mohammad, N. A. Negm and M. R. Mishrif, J. Surfactants Deterg., 2013, 16, 723-731.

9 M. S. Sheikh and K. ud-Din, Colloids Surf., A, 2011, 378, 60-66.

$10 \mathrm{H}$. Gharibi, B. M. Razavizadeh and M. Hashemianzaheh, Colloids Surf., A, 2000, 174, 375-386.

11 B. M. Razavizadeh, M. Mousavi-Khoshdel, H. Gharibi, R. Behjatmanesh-Ardakani, S. Javadian and B. Sohrabi, J. Colloid Interface Sci., 2004, 276, 197-207.

12 B. Sohrabi, H. Gharibi, B. Tajik, S. Javadian and M. Hashemianzadeh, J. Phys. Chem. B, 2008, 112, 1486914876.
13 M. J. Rosen and Q. Zhou, Langmuir, 2001, 17, 3532-3537.

14 Q. Zhou and M. J. Rosen, Langmuir, 2003, 19, 4555-4562.

15 K. L. Mittal, Solution chemistry of surfactants, Plenum Press, New York, 1979, vol. 1.

16 M. J. Rosen and X. Y. Hua, J. Colloid Interface Sci., 1982, 86, 164-172.

17 X. Y. Hua and M. J. Rosen, J. Colloid Interface Sci., 1982, 90, 212-219.

18 M. Shafi Sheikh, K. ud-Din and A. Ahmad Dar, Colloids Surf., A, 2011, 378, 60-66.

19 K. ud-Din, G. Sharma and A. Z. Naqvi, Colloids Surf., A, 2011, 385, 63-71.

20 N. Azum, M. Abdul Rub and A. M. Asiri, Colloids Surf., B, 2014, 121, 158-164.

21 A. Trawinska, E. Hallmann and K. Medrzycka, Colloids Surf., A, 2016, 488, 162-172.

22 N. A. Negm, M. R. Mishrif and D. E. Mohamed, Colloids Surf., A, 2015, 480, 122-129.

23 K. ud-Din, M. S. Sheikh and A. A. Dar, J. Phys. Chem. B, 2010, 114, 6023-6032.

24 A. Bagheri and A. Abolhasani, Korean J. Chem. Eng., 2015, 32, 308-315.

25 P. M. Holland and D. N. Rubingh, J. Phys. Chem., 1983, 87, 1984-1990.

26 M. J. Rosen and J. T. Kunjappu, Surfactants and Interfacial Phenomena, John Wiley \& Sons Press, New Jersey, 4th edn, 2012, ch. 2 .

27 S. R. Patil, N. Buchavzov, E. Carey and C. Stubenrauch, Soft Matter, 2008, 4, 840-848. 